\title{
Análise geológica e geotécnica do cemitério do município de Mandaguari, Estado do Paraná
}

Geologic and geotechnic analysis of the Mandaguari municipality cemetery, State of Parana

\author{
Aline Giseli Martim ${ }^{1}$, Bruno Luiz Domingos de Angelis ${ }^{2}$, \\ Generoso de Angelis Neto ${ }^{3}$, Frederico Fonseca da Silva ${ }^{4}$
}

${ }^{1}$ Geógrafa, Especialista em Planejamento Ambiental, Aluna do Mestrado do PEU - Programa de Pósgraduação em Engenharia Urbana da UEM - Universidade Estadual de Maringá

2 Engenheiro Agrônomo, Doutor em Planejamento de Áreas Verdes - USP, professor e pesquisador da UEM - Universidade Estadual de Maringá, Departamento de Agronomia - DAG

${ }^{3}$ Engenheiro Civil, Doutor em Geotecnia - UEM, Professor e Pesquisador da UEM - Universidade

Estadual de Maringá, Departamento de Agronomia - DAG

${ }^{4}$ Engenheiro Agrônomo, Doutor em Irrigação e Meio Ambiente - UEM, professor e pesquisador do IFPR - Instituto Federal do Paraná.

\section{RESUMO}

Partindo-se do pressuposto que o sepultamento de corpos e a sua subseqüente decomposição em cemitérios horizontais, pode potencialmente causar a contaminação das águas subterrâneas, o presente trabalho teve por objetivo a construção de um laudo geológico para o cemitério horizontal municipal de Mandaguari (Paraná), analisando todas as características geológicas da região onde se instala este empreendimento. Assim, a elaboração deste laudo, ocorreu priorizando o cumprimento das Resoluções 019/04 e 016/05 da Secretaria de Estado do Meio Ambiente e Recursos Hídricos - SEMA e a Resolução 357/05 do Conselho Nacional do Meio Ambiente - CONAMA, a pedido do Instituto Ambiental do Paraná - IAP.

Palavras-chave: Cemitério, Geotecnia, Legislações e Mandaguari

\section{ABSTRACT}

Based on the assumption that the horizontal burial of bodies and their subsequent decomposition into cemeteries can potentially cause contamination of groundwater, this work aims at the construction of a geological report for the horizontal municipal cemetery of Mandaguari (Brazil), analyzing all geological characteristics of the region where was installed this venture. Thus, the preparation of this report, was focus on the enforcement of the Resolutions 019/04 and 016/05 of the Secretary of State for the Environment and Water Resources - SEMA and the Resolution 357/05 of the National Council on the Environment - CONAMA, at the request of the Office for the Environment of Parana - IAP

Key words: Cemetery, Geotechnic, Legislation and Mandaguari. 


\section{INTRODUÇÃO}

A partir do momento que o homem fixa-se em um determinado local, os mortos também se fixam; a priori, acondicionados em cavernas e, posteriormente, em locais específicos próximos às igrejas quando surgem as cidades (MARTIM et al. 2008) Somente a partir deste momento surge então à preocupação em conservação do corpo e, por conseqüência, a idéia de permanência do ideário humano. Isto é, o surgimento do cemitério como símbolo de continuidade destes mortos.

Desta forma, a referida análise geológica e geotécnica tornou-se importante, uma vez que, ao se analisar os parâmetros legais referentes às legislações ambientais como, a Resolução 357/2005, do CONAMA $^{5}$ (BRASIL, 2005), Lei n. 6.938/1981 (BRASIL, 1981), bem como, a norma da CETESB 6 E15.011/1997 (CETESB, 1997) que primam por controlar o lançamento no meio ambiente de poluentes (resíduos sólidos relacionados à exumação dos corpos, incluindo urnas e materiais descartáveis, tais como luvas e sacos plásticos); pela saúde e bem-estar humano; além de buscar o equilíbrio ecológico aquático, em conformidade com as resoluções 019/04 (PARANÁ, 2004) e 016/05 (PARANÁ, 2005) da Secretaria de Estado de Meio Ambiente e Recursos Hídricos do Estado do Paraná que dispõem sobre o licenciamento ambiental de cemitérios, considerando a necessidade de dar efetividade ao princípio da prevenção contra agentes potencialmente poluidores como o produto da coaliquação (também denominado de necrochorume), se terá condições de identificar o meio físico onde o cemitério está ou possa ser implantado, bem como, analisar o conjunto de informações afim de determinar os locais de vulnerabilidade quanto aos aspectos geológicos, geotécnicos e hidrogeológicos.

\section{METODOLOGIA}

A maior parte deste artigo embasou-se na investigação de referências técnicas anteriormente elaboradas e da experiência vivenciada em cerca de dois anos de trabalho e pesquisas acerca dos métodos e legislações para verificação de impactos em cemitérios a serem licenciados.

Com isso, primou-se pela metodologia mais coerente, ou seja, a verificação de aspectos do meio físico ligado a vários ramos da geociência, como: Topografia, Mapeamento Geológico, Geomorfologia, Meteorologia e Hidrogeologia.

Salienta-se ainda a realização de pesquisas em órgãos públicos como o IAP - Instituto Ambiental do Paraná; IBGE - Instituto Brasileiro de Geografia e Estatística, e a execução de Sondagens do tipo SPT - Standart Penetration Test e Testes de Infiltração, e uso da elaboração do banco de dados no SIG (Sistema de Informação Geográfica) Spring 5.06 (CAMARA et al., 1996) de acordo com as legislações estaduais vigentes.

A partir do exposto verificou-se que o cemitério horizontal público do município Mandaguari (PR), com área de, aproximadamente, 36.683,25 $\mathrm{m}^{2}$ encontra-se inserido na Região Noroeste do Estado - 3ํㅜ Planalto Paranaense, mais especificamente no Lote 34-A, do município e apresenta uma área de $335,814 \mathrm{~km}^{2}$ (IBGE, 2015).

\section{RESULTADOS E DISCUSSÕES}

\subsection{Quanto à Geomorfologia}

Em relação aos critérios geológicos observados trata-se de uma região de solo argiloso, com baixa permeabilidade e o lençol freático abaixo dos $15 \mathrm{~m}$. de profundidade, não apresentando sinais de erosão (nem sulcos, ravinas ou voçorocas), levando também a uma excelente classificação da área segundo Miotto (1990) e parâmetros da CETESB (1989) .

CONAMA - Conselho Nacional do Meio Ambiente

CETESB - Companhia Ambiental do Estado de São Paulo 
O local de análise se caracteriza por uma topografia levemente acentuada, tendendo a plana, inserida num flanco, em vale aberto, estando o ponto mais elevado a cerca de $750 \mathrm{~m}$ e o mais baixo a 735,3 m, possuindo um desnível absoluto de $15,3 \mathrm{~m}$.

Já a declividade apresenta-se de forma convexa regular com valores inferiores a 2,5\% sendo classificada, segundo Seignemartin (1979), como Classe 1 - ótima para a instalação de equipamentos urbanos.

De acordo com Petsch et al. (s.d.), a declividade é um dos fatores limitantes para implantação de um cemitério, pois locais com declive acentuado podem ser indicativos de solos rasos e proximidade do lençol freático e também aceleração de processos erosivos.

Interessante observar que a Norma Técnica 11.0940/89 da CETESB (CETESB, 1989) cita como ideal as declividades de, no mínimo, $5 \%$ e, no máximo, 15\% para a implantação de cemitérios horizontais.

Contudo, dados técnicos mostram ser uma região apta a receber a instalação de equipamentos urbanos, achando-se numa faixa ótima para sistemas de saneamento e instalações subterrâneas.

Geomorfologicamente, o empreendimento insere-se na área de abrangência da Bacia Hidrográfica do Rio Pirapó, que perfaz cerca de 168 km e cujo nome deriva da bacia do Rio Pirapó, que nasce a $900 \mathrm{~m}$ de altitude no município de Apucarana. Orienta-se para Noroeste, desaguando no rio Paranapanema, a $250 \mathrm{~m}$ no município de Jardim Olinda. A área da bacia em questão é a mais densamente povoada do estado.

\subsection{Quanto ao Tipo Climático}

No que diz respeito ao tipo climático da região, no município de Mandaguari, onde se localiza o empreendimento destinado ao estudo, primou-se pelo sistema de classificação Köeppen (IAPAR, 2006), uma vez que, através de um código de letras que designam grandes grupos e subgrupos climáticos. Esta classificação apresenta subdivisões para distinguir características estacionais de temperatura e pluviosidade Trewatha e Horn (1980).

Deste modo, verifica-se então que o referido empreendimento urbano encontra-se inserido na área de atuação do Clima Úmido, em todas as estações do ano - Cfa.

O clima $C f a$, clima tropical, com temperatura média no mês mais frio abaixo de $18^{\circ} \mathrm{C}$ (mesotérmico), com verões quentes e chuvosos e temperatura média no mês mais quente acima de $22^{\circ} \mathrm{C}$ e sem estação seca definida.

\subsubsection{Caracterização pluviométrica}

Os dados de precipitação foram extraídos da base de dados do Simepar (SIMEPAR, 2015). A Figura 1 demonstra que a precipitação anual na região é elevada para os padrões do estado, variando de 1550 a 2700 mm/anuais. 


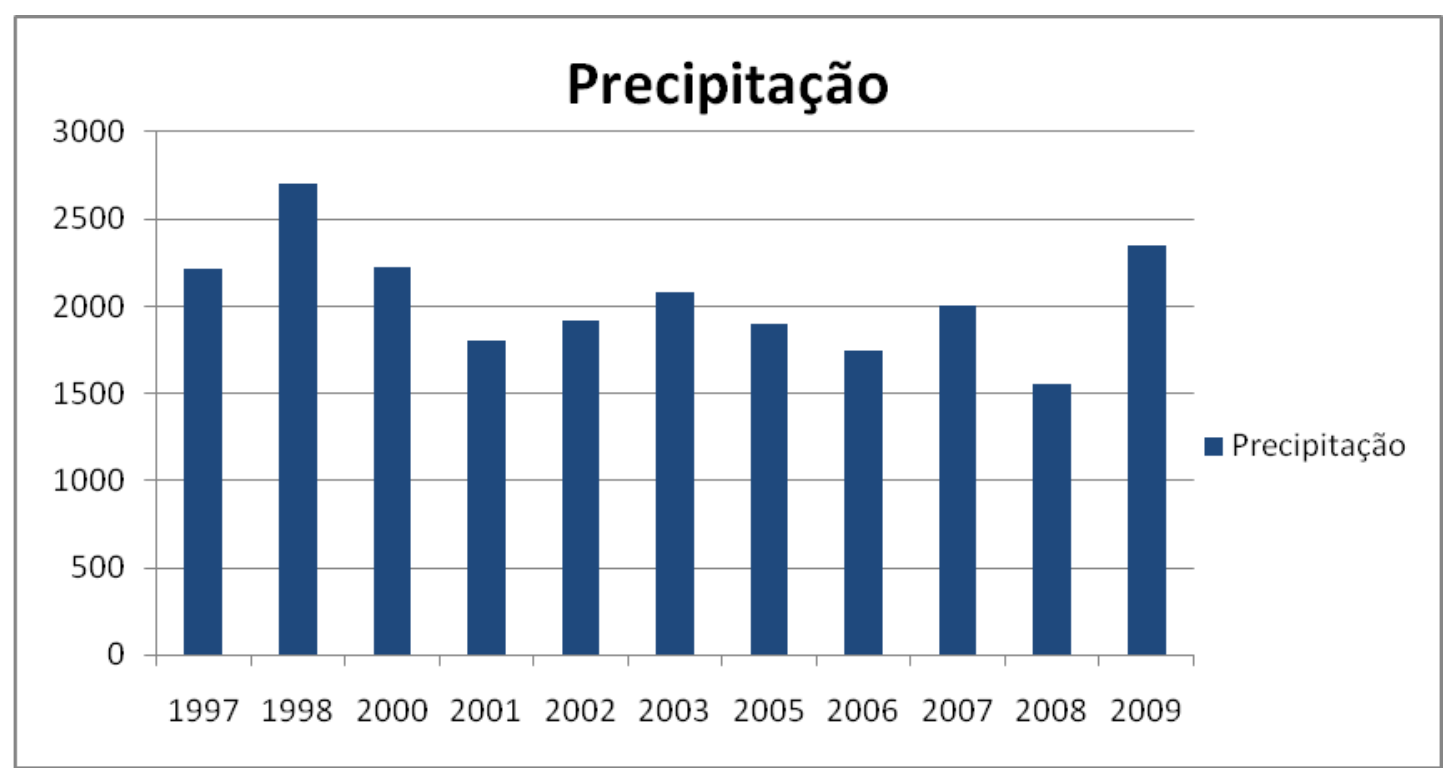

Figura 1. Dados pluviométricos da área de estudo (1997-2009).

\subsection{Quanto a Geologia}

Geologicamente a área apresenta dois tipos de formação: Caiuá e a Serra Geral onde inserese o município de Mandaguari.

A formação Serra Geral engloba as rochas correlacionadas com o "Trapp basáltico" toleítico, onde se verifica a predominância de rochas de textura microcristalina e uma estrutura consideravelmente maciça, o que reflete a gênese através de derrames de lava sucessivos e intermitentes, segundo Leinz (1949).

Segundo Fraga (1986), tais derrames constituem unidades sobrepostas posicionados lateralmente e cuja continuidade vertical é limitada.

A conformidade entre composição de gases, movimento e resfriamento da lava, pode se caracterizar estruturalmente em zonas. Uma zona basal, uma zona intermediária e uma zona de topo de derrame com vesículas e/ou amígdalas, conforme Albuquerque Filho e Azevedo (1987).

Segundo Rebouças (1994), a espessura dessas seqüências de derrames alcança $1.000 \mathrm{~m}$. nas regiões centrais da Bacia do Paraná.

De acordo com Dutra et al. (s.d), o topo, geralmente constituído por amídalas com ou sem vesículas e, às vezes com arenito intertrapiano; $\mathrm{O}$ núcleo é constituído por rocha microcristalina compacta; e a base é constituída de basalto vesicular e amigdaloidal.

Superficialmente, verifica-se a presença dos tipos de solo Latossolo Roxo e de Terra Roxa estruturada, oriundos da rocha basáltica, com argila marrom escura mole, com consistência média a cerca de 3,0 m. de profundidade.

Miotto (1990) cita as argilas como muito favoráveis ao desenvolvimento dos processos de saponificação.

Localmente, o substrato é composto de basaltos que possuem relativa uniformidade na composição. Estima-se que a rocha sã esteja a uma profundidade abaixo de $15,00 \mathrm{~m}$, conforme se observa nas sondagens realizadas no local de análise.

São caracterizados como da superfície até os $8 \mathrm{~m}$. (espessura da cobertura inconsolidada), como fofo; dos 8 até os $13 \mathrm{~m}$. de profundidade, como pouco compacto; e, dos 13 até $15 \mathrm{~m}$., como medianamente compacto, segundo indicação de Yamada (2004).

As locações destes ensaios na carta da locação das sondagens geológicas e teste de infiltração são apresentados nas Figuras 2, 3, 4 e 5. 


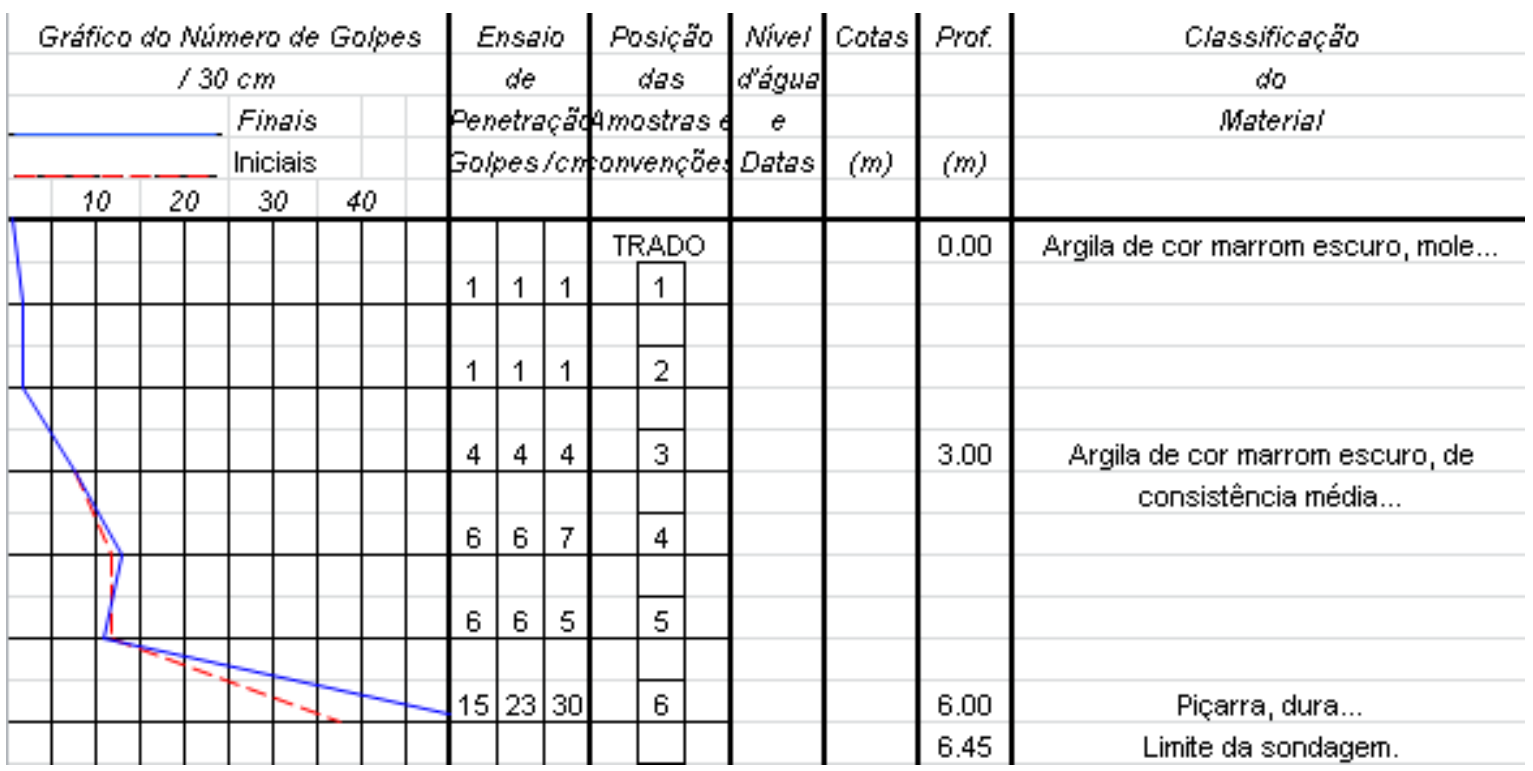

Figura 2. Número de Golpes à profundidade de 0,0 a 6,0 m. no Ponto 1

Na classificação do material no ponto 1, gerador da Figura 2, observa-se que no intervalo de 0,0 a 3,0 m. o solo se caracteriza por ser Argila de cor marrom escuro, mole; de 3,0 a 6,0 m, o solo se caracteriza por ser argila de cor marrom escuro, de consistência média; e, a partir de 6,0 m observouse a existencia piçarra, solo duro, caracterizando o limite da sondage a $6,45 \mathrm{~m}$. de profundidade.

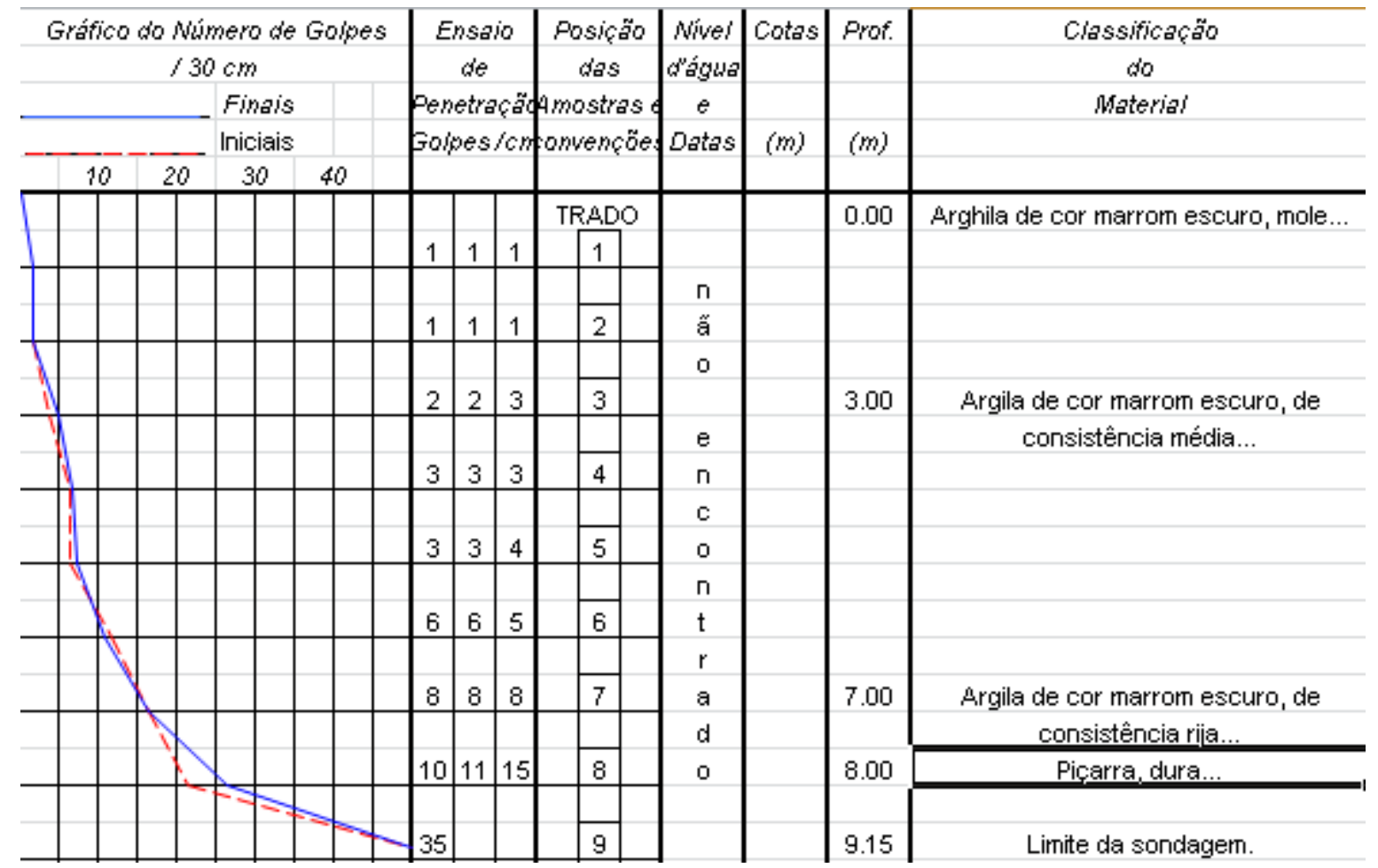

Figura 3. Número de Golpes à profundidade de 0,0 a 9,15 m. no Ponto 2

Na classificação do material no ponto 2, gerador da Figura 3, observa-se que no intervalo de 0,0 a 3,0 m o solo se caracteriza por ser Argila de cor marrom escuro, mole; de 3,0 a 7,0 m, o solo se caracteriza por apresentar argila de cor marrom escuro, de consistência média; de 7,0 a 8,0 m observou-se a existencia Argila de cor marrom escuro, de consistência rígida; e, a partir de 8,0 m. encontrou-se Piçarra, dura, finalizando a sondagem a 9,15m. de profundidade. 


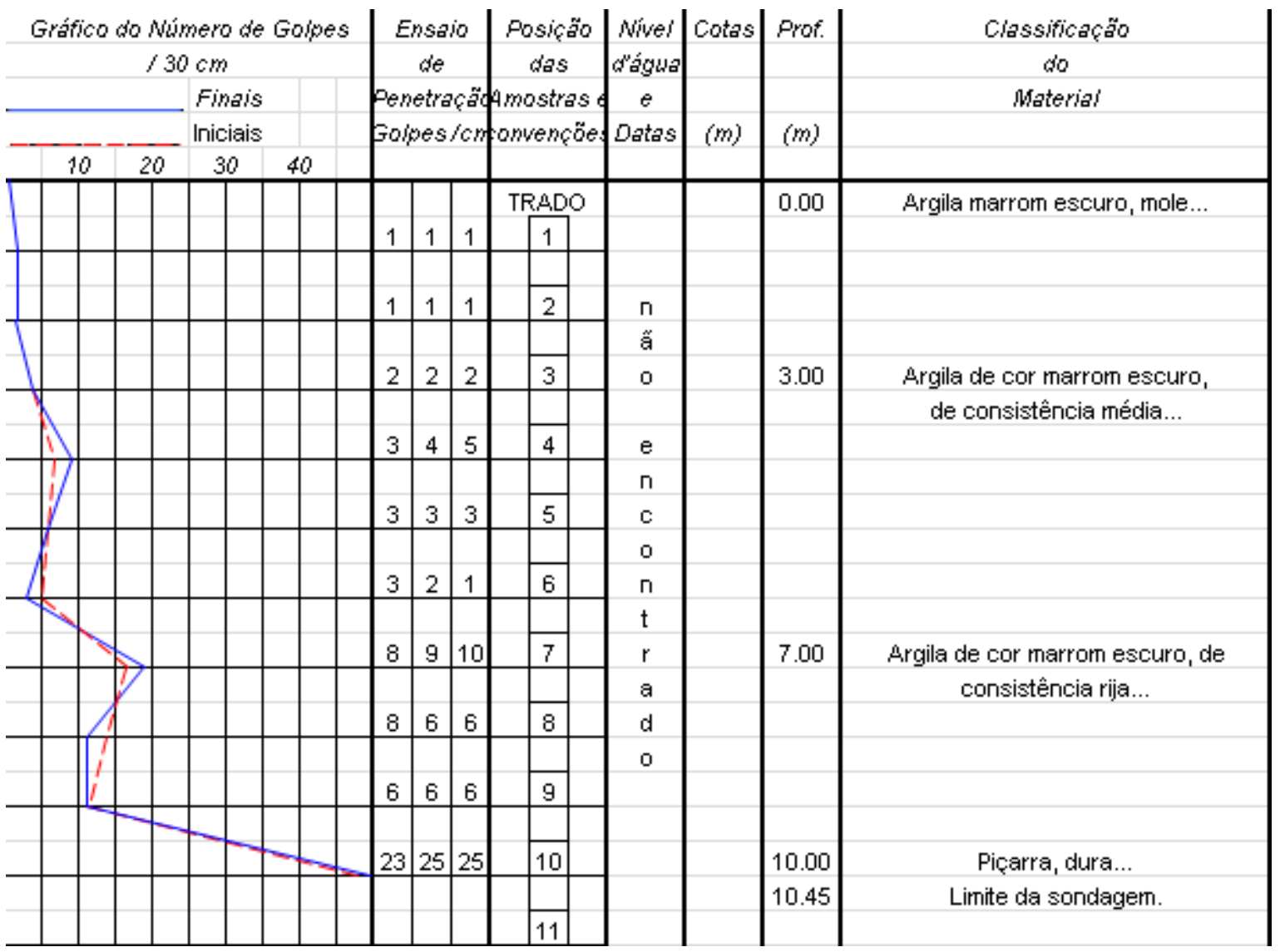

Figura 4. Número de Golpes à profundidade de $0,0 \mathrm{a} 10,45 \mathrm{~m}$. no Ponto 3

Na classificação do material no ponto 3, gerador da Figura 4, observa-se que no intervalo de 0,0 a 3,0 m. o solo se caracteriza por ser Argila de cor marrom escuro, mole; de 3,0 a 7,0 m, o solo se caracteriza por ser argila de cor marrom escuro, de consistência média; de 7,0 a 10,0 m observou-se a existencia de soloque se caracteriza por ser argila de cor marrom escuro, de consistência rígida; e, a paritr de $10 \mathrm{~m}$. encontrou-se Piçarra dura, finalizando a sondagem a 10,45 m.

\begin{tabular}{|c|c|c|c|c|c|c|c|c|c|c|c|c|}
\hline \multicolumn{5}{|c|}{ Gráfico do Múmero de Goipes } & \multicolumn{3}{|c|}{ Ensaio } & Posiçäo & \multirow{2}{*}{$\begin{array}{l}\text { Nivel } \\
\text { d'água }\end{array}$} & \multirow[t]{2}{*}{ Cotas } & \multirow[t]{2}{*}{ Prof. } & \multirow{2}{*}{$\begin{array}{c}\text { Classificação } \\
\text { do }\end{array}$} \\
\hline \multicolumn{5}{|c|}{$/ 30 \mathrm{~cm}$} & & de & & das & & & & \\
\hline & & & Finais & & \multicolumn{3}{|c|}{ Penetraçäo } & Amostrase & e & & & Material \\
\hline & & \multicolumn{3}{|c|}{ Iniciais } & \multirow{2}{*}{\multicolumn{3}{|c|}{ Goipes $/ \mathrm{cm}$}} & convençöes & Datas & $(m)$ & $(m)$ & \\
\hline 10 & & & 30 & 40 & & & & & & & & \\
\hline & & & & & & & & TRADO & & & 0.00 & Argila de cor marrom escuro, mole. \\
\hline & & & & & 2 & 2 & 2 & 1 & & & & \\
\hline & & & & & & & & & & & & \\
\hline & & & & & 1 & 1 & 1 & 2 & $\mathrm{n}$ & & & \\
\hline & & & & & & & & & ă & & & \\
\hline & & & & & 3 & 3 & 3 & 3 & 0 & & 3.00 & Argila de cor marrom escuro, de \\
\hline & & & & & & & & & & & & consistência média.. \\
\hline & & & & & 8 & 7 & 7 & 4 & $\mathrm{e}$ & & 4.00 & \\
\hline & & & & & & & & & $n$ & & & \\
\hline & & & & & 4 & 4 & 4 & 5 & c & & & \\
\hline & & & & & & & & & 0 & & & \\
\hline & & & & & 9 & 9 & 9 & 6 & $n$ & & & Argila de cor marrom escuro, de \\
\hline & & & & & & & & & $t$ & & & consistência rija.. \\
\hline & & & & & 15 & 20 & 25 & 7 & $\mathrm{r}$ & & & Piçarra, dura. \\
\hline & & & 1 & & & & & & a & & 7.80 & Limite da sondagem. \\
\hline
\end{tabular}

Figura 5. Número de Golpes à profundidade de 0,0 a 7,80 m. no Ponto 4 
Na classificação do material no ponto 4, gerador da Figura 5, observa-se que no intervalo de 0,0 a 3,0 m. o solo se caracteriza por ser Argila de cor marrom escuro, mole; de 3,0 a 4,0 m, o solo se caracteriza por ser argila de cor marrom escuro, de consistência média; de 4,0 a 7,0 m observou-se a existencia de soloque se caracteriza por ser argila de cor marrom escuro, de consistência rígida; e, a paritr de 7,0 m. encontrou-se Piçarra dura, finalizando a sondagem a 7,80 m.

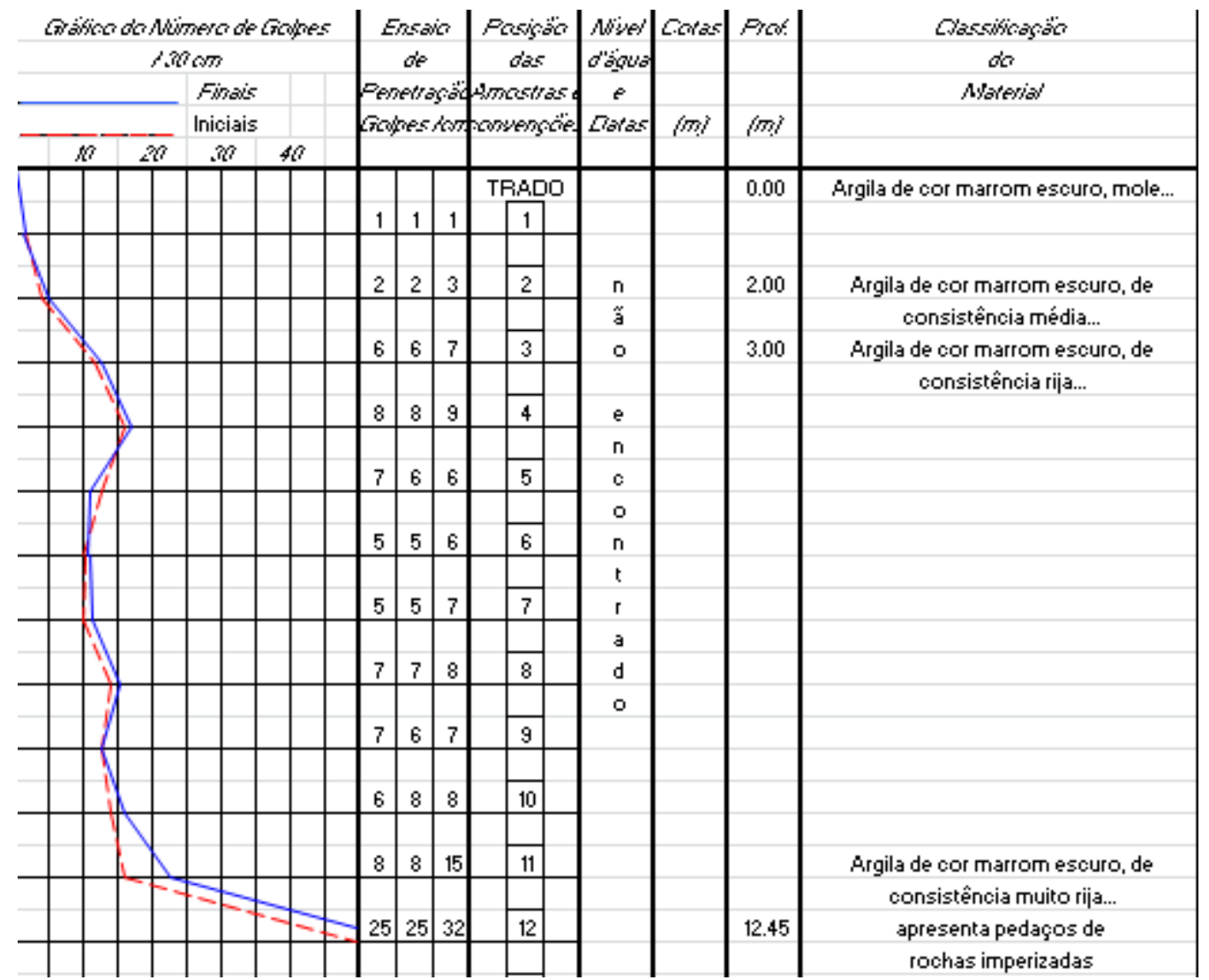

Figura 6. Número de Golpes à profundidade de 0,0 a $12,45 \mathrm{~m}$. no Ponto 5

Na classificação do material no ponto 5, gerador da Figura 6, observa-se que no intervalo de 0,0 a 2,0 m. o solo se caracteriza por ser Argila de cor marrom escuro, mole; de 2,0 a 3,0 m, o solo se caracteriza por ser argila de cor marrom escuro, de consistência média; de 3,0 a 10,0 m observou-se a existencia de solo que se caracteriza por ser argila de cor marrom escuro, de consistência rígida; de 10,0 a 12,0 o solo se caracteriza por ser argila de cor marrom escuro de consistência muito rigida; e, a paritr de 12,0 m. encontrou-se a presença de pedaços de rochas inteperizadas, finalizando a sondagem a $12,45 \mathrm{~m}$.

Realizado o teste de infiltração, obteve-se o tempo de $6^{\prime} 59^{\prime \prime}$ para penetração de $1,0 \mathrm{~cm}$ de molhabilidade, detectado até a profundidade de 1,50 m.

Assim, a partir desta caracterização definiu-se executar 03 (três) ensaios de teste de percolação devido à geomorfologia uniforme do terreno. A forma como foram executados os ensaios é descrito na norma ABNT - NBR 7229/82 (ABNT, 1982).

Contudo, adotou-se o menor dos coeficientes determinados nos ensaios, obtendo os resultados que podem ser observados na Tabela 1.

Tabela 1. Indicação dos ensaios, tempo de infiltração, coeficiente.

\begin{tabular}{ccc}
\hline ENSAIO & TEMPO & COEFICIENTE \\
\hline CX -01 & $3^{\prime} 56^{\prime \prime}$ & $74,001 / \mathrm{m}^{2}$.dia \\
CX -02 & $3^{\prime} 56^{\prime \prime}$ & $74,001 / \mathrm{m}^{2}$.dia \\
\hline
\end{tabular}

Fonte: os autores 
De acordo com os tempos encontrados no ensaio, obteve-se o tempo mais crítico para o rebaixamento de $1,0 \mathrm{~cm}$ na caixa de teste 02 , indicando que o coeficiente de infiltração para a situação mais crítica do terreno em analise é de $74,001 / \mathrm{m}^{2}$.dia.

Com respeito ao risco de erosão, a área em questão pode ser classificada como zona estável, por apresentar uma declividade classificada de média a baixa.

Também na região de implantação do cemitério e ao seu entorno não se observou nenhum processo erosivo.

Quanto ao abastecimento de água do cemitério de Mandaguari, o mesmo tem seu abastecimento realizado pela empresa concessionária do estado (SANEPAR), através da ligação direta da rede de fornecimento de água às torneiras e banheiros existentes, já que o cemitério municipal é desprovido de caixa de armazenamento de água, bem como de poço tubular profundo.

Quanto à área circunvizinha apresenta: à frente do cemitério se encontra um colégio (Colégio Sagrada Família) e lotes residenciais; lateralmente encontra-se outra unidade de ensino (Colégio Estadual Vera Cruz) e um lote sem edificação que é utilizado como horta municipal; e, ao fundo, se encontram apenas áreas agrícolas.

Com relação à drenabilidade, estudada por Godoy (1989), apresenta-se como área permeável, ou melhor, de média drenabilidade, sendo esta uma característica favorável ao local de análise.

Por fim, salienta-se que não existe nenhum sistema de drenagem das águas pluviais na área.

As águas pluviais que correm nas áreas permeáveis são infiltradas no solo. Já as águas que caem nas áreas impermeáveis são escoadas para as passarelas e, deste ponto, são lançadas para fora do cemitério em locais ao fundo e nas laterais, como pode se observar nas Figuras 7, 8, 9, 10 e 11.

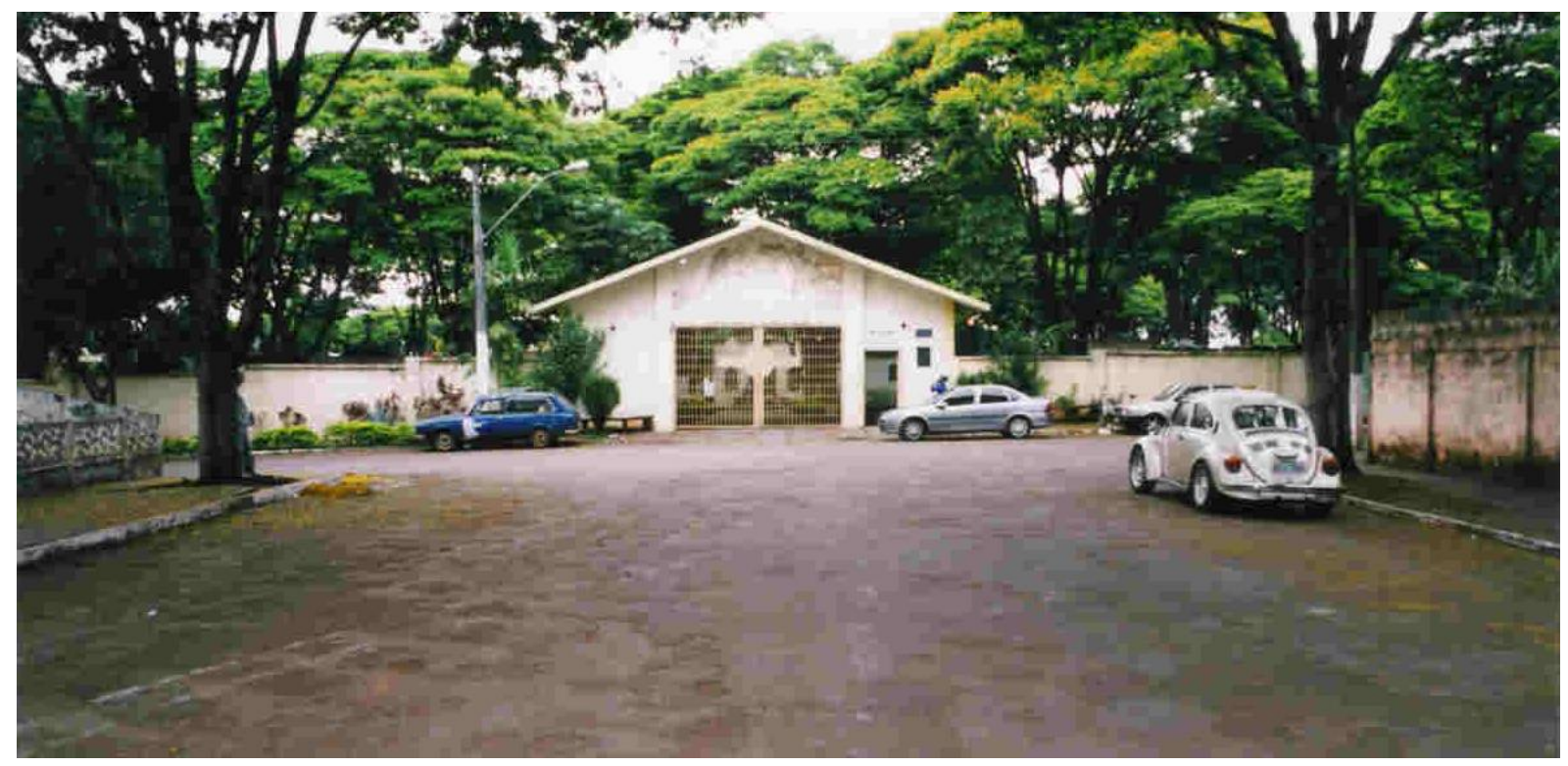

Figura 7. Pórtico de entrada.

Fonte: os autores 


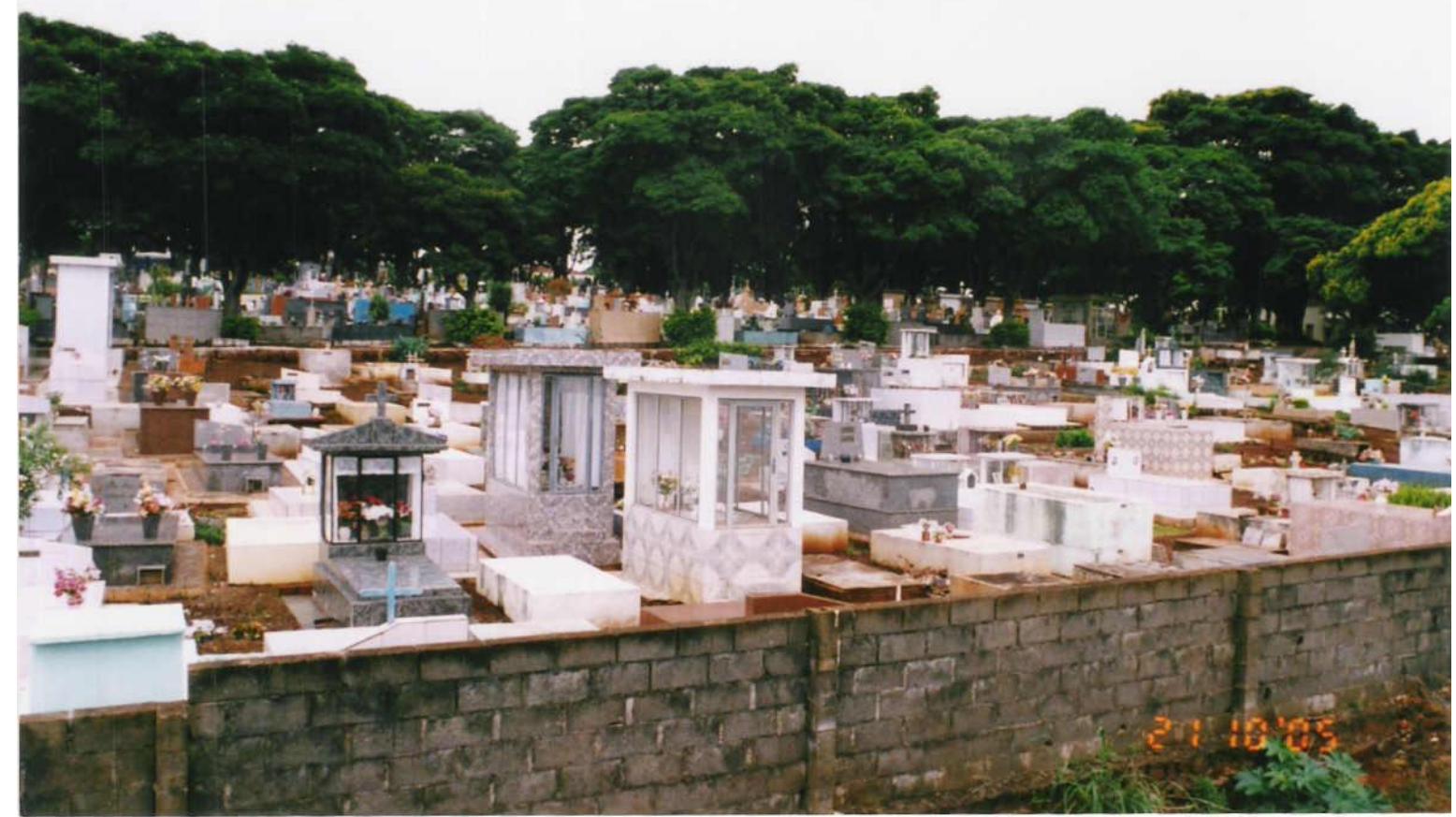

Figura 8. Visão párcial dos túmulos e do muro.

Fonte: os autores

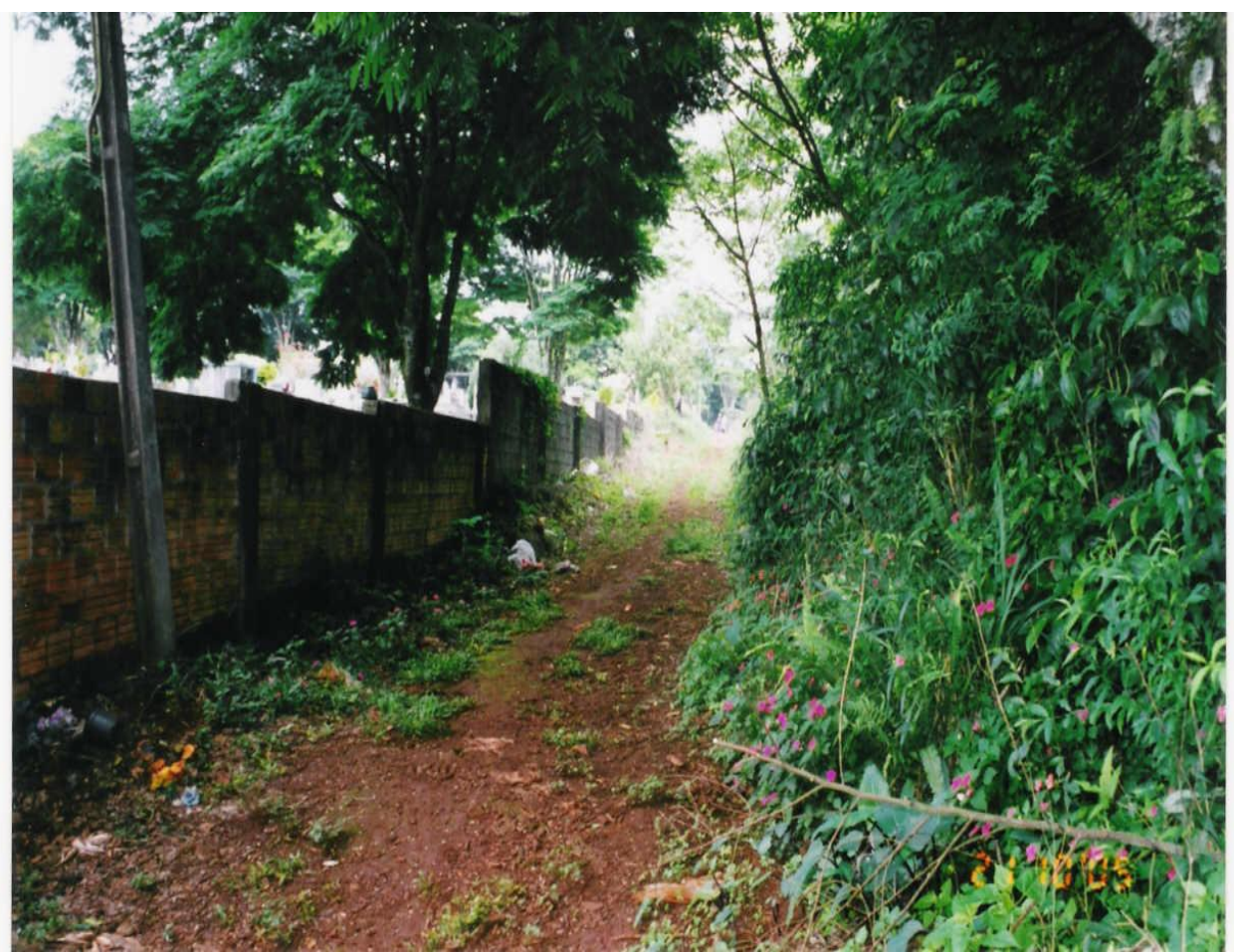

Figura 9. Visualização da área lateral ao cemitério.

Fonte: os autores 


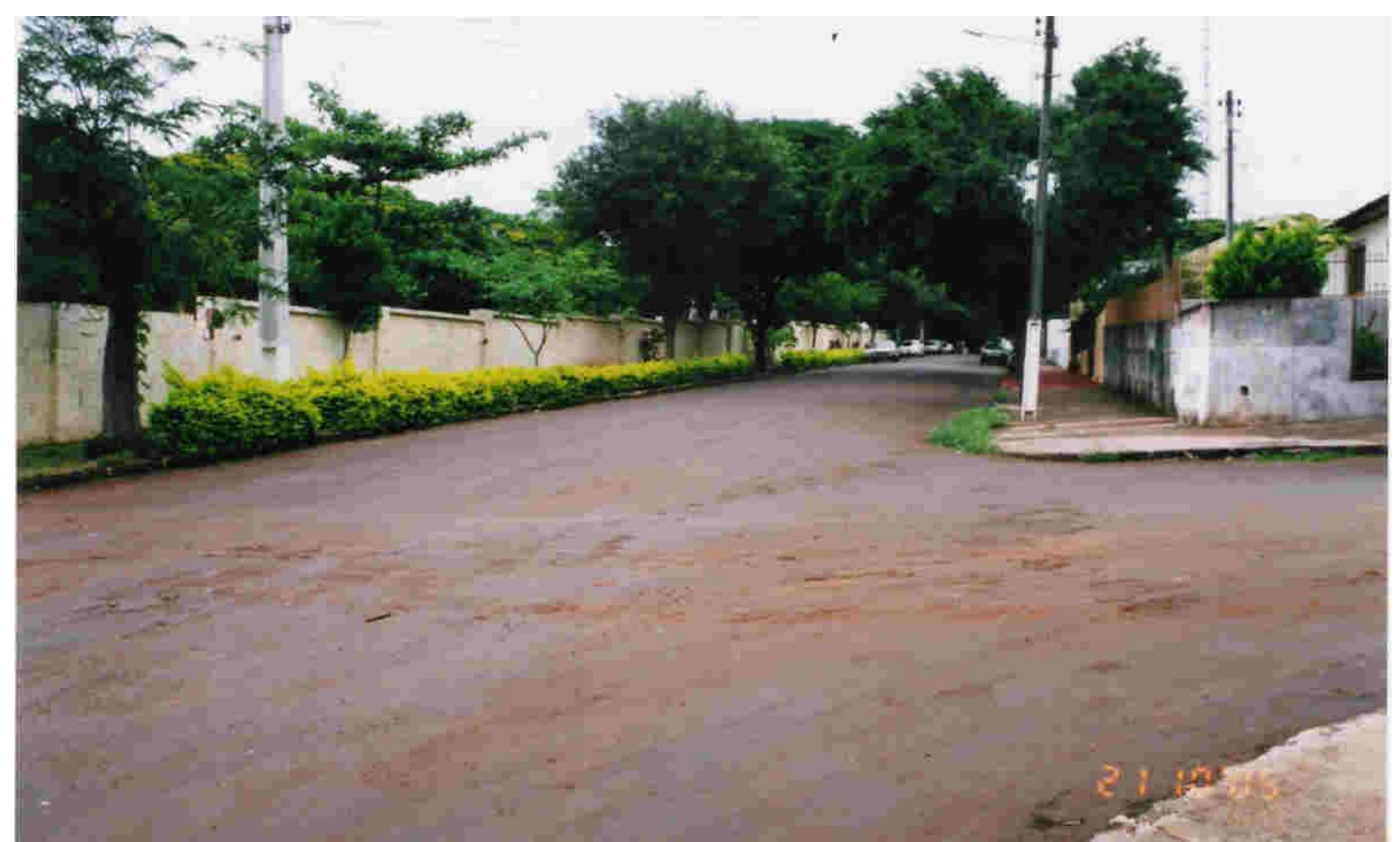

Figura 10. Visualização da área lateral ao cemitério.

Fonte: os autores

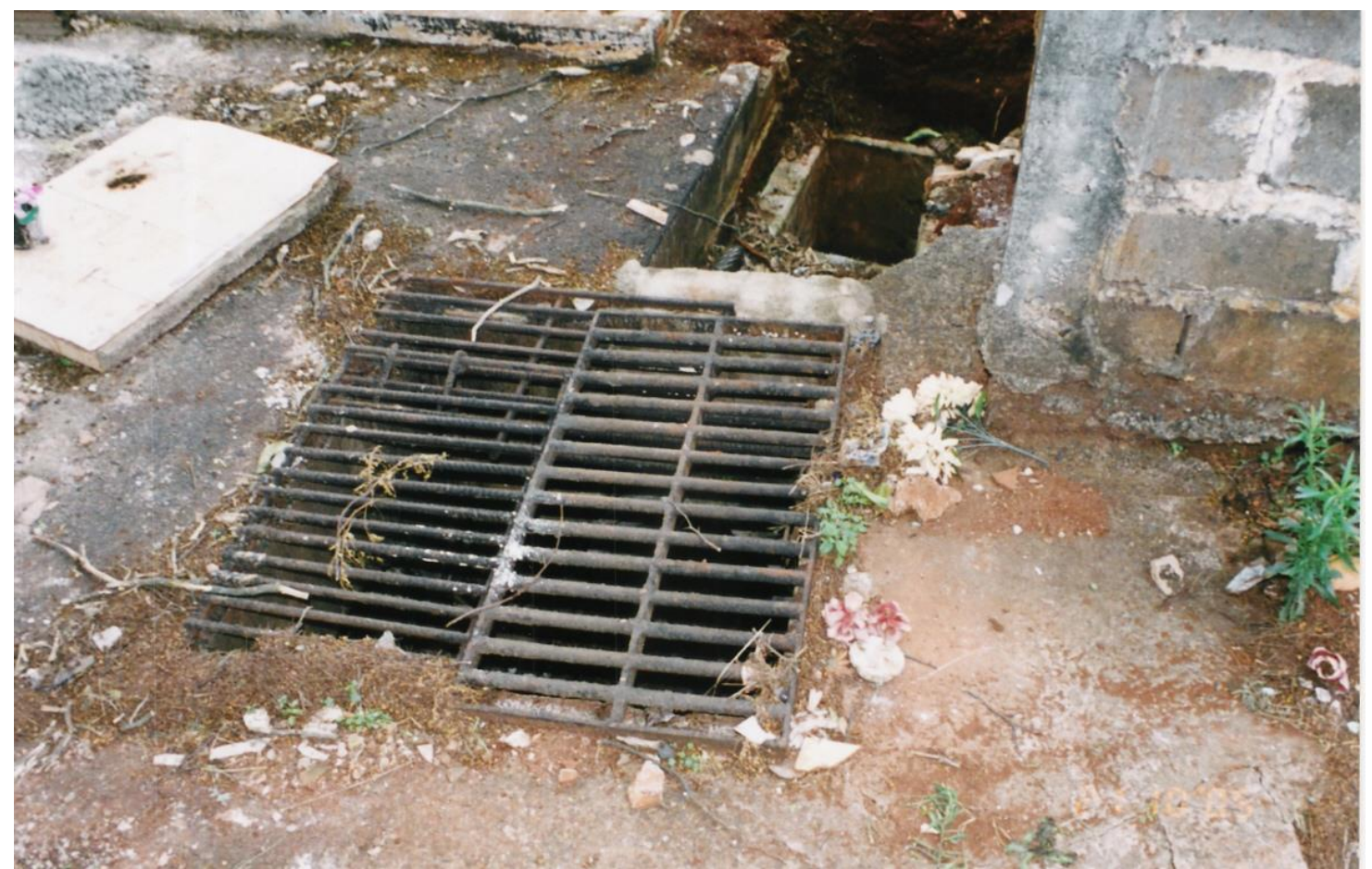

Figura 11. Condições da drenagem.

Fonte: os autores

\section{CONSIDERAÇÕES FINAIS}

Observou que os túmulos apresentam-se, na maioria, em bom estado de conservação, não se observando rachaduras e/ou recalques. Foram muito poucas as sepulturas encontradas em situação de abandono e degradadas pelo tempo. 
Outro aspecto a ressaltar é que, de acordo com as observações realizadas no cemitério de Mandaguari notou-se que as sepulturas novas, apresentavam o seu fundo em contato direto com o solo.

Quanto à declividade observada mostra uma região apta a receber a instalação de equipamentos urbanos, achando-se numa faixa ótima para sistemas de saneamento e instalações subterrâneas.

Com relação à drenabilidade, apresenta-se como área permeável, média à permeável, sendo esta uma característica favorável ao local de análise.

O lençol freático não se apresentou até a profundidade de $15 \mathrm{~m}$.

A profundidade da cobertura inconsolidada é maior que $3 \mathrm{~m}$ abaixo das covas (cerca de 1,50 $\mathrm{m}$ de profundidade), pois apresenta-se, em média, com 8 a $15 \mathrm{~m}$.

Desta maneira e, como foi caracterizado pelos ensaios realizados, esta área pode continuar sendo utilizada como cemitério devendo, para tanto, providenciar um sistema de monitoramento do seu lençol freático, tratamento adequado de efluentes líquidos oriundos dos banheiros, plano de gerenciamento de resíduos sólidos e plano de manutenção das instalações físicas.

\section{REFERÊNCIAS}

ABNT - Associação Brasileira de Normas Técnicas. NBR 7229/82 Projeto, construção e operação de sistemas de tanques sépticos. Disponível em: http://www.acquasana.com.br/legislacao/nbr_7229.pdf e acessado em 07 jun 2014.

ALBUQUERQUE FILHO, J.L.; AZEVEDO, A.A. Águas Subterrâneas In: OLIVEIRA, A M. S.; Britto, S. N. A. Geologia de engenharia. São Paulo: ABGE-Associação Brasileira de Geologia e Engenharia, 1996.p.111-130.

BRASIL. Resolução CONAMA 357/2005 - Ministério do Meio Ambiente. Dispõe sobre a conservação Dos recursos hídricos. Disponível em: www.mma.gov.br/port/conama/res/res05/res35705.pdf e acessado em 08 abr. 2014.

Lei № 6.938 de 31 de agosto de 1981. Dispõe sobre a Política Nacional do Meio Ambiente, seus fins e mecanismos de formulação e aplicação, e dá outras providências. Disponível em: http://www.planalto.gov.br e acessado em: 14 abr. 2014.

CÂMARA, G.; SOUZA, R.C.M.; FREITAS, U.M.; GARRIDO, J.C.P. SPRING: Integrating Remote Sensing and GIS with Object-Oriented Data Modelling. Computers and Graphics vol.15, n.6, July 1996, pp.13-22.

CETESB - Companhia Estadual de Saneamento Ambiental. Implantação e Operação de Cemitério.Procedimentos. São Paulo:CETESB. 1989.

Norma Técnica E15.011/1997. Disponível em: http://www.cetesb.sp.gov.br/servicos/normastecnicas-cetesb/normas-tecnicas-vigentes/ e acesso em 10 out 2013.

DUTRA, C.R.; MESQUITA, M.J.; GOMES, M.E.B.; FERREIRA, C.H.N.; ARIOLI, E.E.; BONGIOLO, E.M. Classificação de brechas em ambiente vulcânico e interação lava-sedimento na região de Salto Segredo-PR. Disponível em: http://www.cprm.gov.br/publique/media/evento_1339.pdf e acessado em 20 out 2014.

FRAGA, C.G. Introdução ao zoneamento do sistema aquífero Serra Geral no Estado do Paraná. Dissertação de Mestrado, São Paulo, 1986.

GODOY, M.C.T.F. Mapeamento Geotécnico Preliminar da Região Urbana de Presidente Prudente. Universidade de São Paulo, Escola de Engenharia de São Carlos - SP. Dissertação. 1989.

IBGE - Instituto Brasileiro de Geografia e Estatística. 2015. Cidade de Mandaguari. Disponível em: http://cidades.ibge.gov.br/xtras/perfil.php?codmun=411420 e acesso em 13 set 2015. 
IAPAR - Instituto Agronômico do Paraná - Classificação Climática, segundo Koeppen, in: http://200.201.27.14/Site/Sma/Cartas_climáticas/Classificação_Climática.htm, em 27 mar 2006.

LEINZ, V. Contribuição à geologia dos derrames basálticos do sul do Brasil. Boletim da Faculdade de Filosofia, Ciências e Letras. São Paulo, 1949.

MARTIN, A.G. Aspectos do Meio Físico a serem observados para Implantação de Cemitérios Horizontais. Agro@mbiente On-line, vol.2, no. 1, P.95-101. jan/jun, Boa Vista, 2008.

MIOTTO, S.L. Aspectos geológico-geotécnicos da determinação da adequabilidade de áreas para a implantação de cemitérios. Dissertação. UNESP-campus de Rio Claro. 1990.

PARANÁ. Resolução estadual.no ${ }^{019} / 04$, de 04 de maio de 2004. Dispõe sobre o licenciamento Ambiental de Cemitérios. Disponível em < http://www.pr.gov.br/sema/>. Acessado em: 12 out 2012.

Resolução estadual no 016/05, de 03 de outubro de 2005. Dispõe sobre o licenciamento Ambiental de Cemitérios. Disponível em < http://www.pr.gov.br/sema/>. Acessado em: 12 out 2012.

PETSCH, C.; MONTEIRO, J.B.; BUENO, M.B. [s.d.] Cemitérios e a questão do planejamento territorial em pequenas bacias: o caso do córrego Sussuí - Engenheiro Beltrão - PR. Disponível em: http://www.revista.ufpe.br/rbgfe/index.php/revista/article/downloadSuppFile/180/37. E acessado em 02 jun 2015.

REBOUÇAS, A.C. Water crisis: facts and myths. An. Acad. bras. Ci. 66, Sup. 1. p 135- 147, 1994.

SEIGNEMARTIN, C.L. Geologia de áreas urbanas: o exemplo de Ribeirão Preto. Tese de doutoramento, SP, 1979.

SIMEPAR - Dados pluviométricos de Mandaguari. Disponível em: http://www.simepar.br/verao/internas/conteudo/meteorologia/tempo.shtml?id=4114203 e acessado em 13.jun 2015.

TREWARTHA, G.T.; HORN. L.H. 1980. An introduction to climate. New York, McGraw-Hill, $5^{\text {th }}$ ed., 416p.

YAMADA, D.T. Caracterização geológico-geotécnica aplicada á instalação de postos de combustíveis em Rio Claro (SP). Instituto de Geociências, campus de Rio Claro - SP. Dissertação. 2004. 